\title{
New Advances in the Precision Medicine of Lung Cancer
}

\author{
Philip T. Cagle • Timothy Craig Allen • \\ Randall J. Olsen
}

Published online: 24 December 2012

(c) Springer Science+Business Media New York 2012

\begin{abstract}
First-generation tyrosine kinase inhibitors (TKIs) effective against non-small cell lung cancers (NSCLC) with epidermal growth factor receptor mutations or anaplastic lymphoma kinase fusion genes were initial steps in the precision medicine of lung cancer, but have significant limitations. Only about $19 \%$ of NSCLC demonstrate predictive biomarkers that indicate that they are likely to respond to first-generation TKIs, and virtually all NSCLC that initially respond develop acquired resistance after several months. Ongoing developments in this field are expected to provide patients with improved diagnosis and treatment options. Next-generation sequencing offers superior options for genotyping tumors. Immunohistochemistry promises to allow predictive biomarkers analysis by direct observation of malignant cells using conventional tools and procedures. Treatment options that include repurposing of drugs for new targets and investigation of new clinically actionable targets will require greater knowledge and participation of the pathologist in personalized healthcare of lung cancer patients.
\end{abstract}

\footnotetext{
P. T. Cagle $(\varangle) \cdot$ R. J. Olsen

Department of Pathology and Genomic Medicine,

The Methodist Hospital, Houston, TX 77030, USA

e-mail: pcagle@tmhs.org

R. J. Olsen

e-mail: rjolsen@tmhs.org

P. T. Cagle - R. J. Olsen

Department of Pathology and Laboratory Medicine,

Weill Medical College of Cornell University,

New York, NY, USA

T. C. Allen

Department of Pathology, The University of Texas Health

Science Center, Tyler, TX 75708-3154, USA

e-mail: timothy.allen@uthct.edu
}

Keywords Lung cancer - Predictive biomarker . Personalized healthcare $\cdot$ Targeted therapy $\cdot$ Next generation sequencing

\section{Introduction}

Lung cancer has long been the leading cause of cancer death in the United States, responsible for greater mortality than the combined total of the next three most common types (colon, breast and prostate cancers) [1]. Lung cancer is also the leading cause of cancer deaths worldwide [2]. The overall five-year survival has remained a dismal 10-15\% for decades, because most patients present with advanced disease and treatment options are limited [3,4]. Thus, it is not surprising that the advent of targeted molecular therapies for lung cancer has generated tremendous excitement. Predictive biomarker testing on pathology specimens has substantially altered the role of pathologists in lung cancer patient care.

The first strides toward a successful specific molecular therapy in lung cancer have been achieved with tyrosine kinase inhibitors (TKIs) against the epidermal growth factor receptor (EGFR). These include gefitinib (Iressa; AstraZeneca, London, UK) and erlotinib (Tarceva; Genentech, South San Francisco, CA and OSI Pharmaceuticals, Long Island, NY). Approximately $85 \%$ of lung malignancies are non-small cell lung cancers (NSCLC). EGFR overexpression in the majority of NSCLCs was first recognized in the 1980s [5], but early clinical trials with EGFR TKIs demonstrated only modest results. However, in 2004, several independent investigators reported that the presence of EGFR gene somatic mutations predicted a significant response of NSCLCs to EGFR TKIs [6-8]. Since 2009, 
multiple clinical trials have confirmed better response rates (RR) and progression-free survival (PFS) in patients receiving EGFR TKIs versus conventional therapy if their advanced stage NSCLC has EGFR mutations [9•, 10, 11]. Importantly, clinical trials have demonstrated that $E G F R$ mutation analysis, rather than copy number alterations by fluorescent in situ hybridization (FISH) or overexpression by immunohistochemistry (IHC), is the most reliable method of determining which NSCLC are likely to respond to TKI therapy $[3,4,12,13]$.

Another target for TKI therapy for NSCLC, anaplastic lymphoma kinase (ALK), was reported in 2007. ALK was first described with the fusion partner echinoderm microtubule-associated protein-like 4 (EML4) [14]. Subsequently, multiple variants of the EML4-ALK gene rearrangement, as well as other ALK fusion partners, have been described in NSCLC [15]. The food and drug administration (FDA) accelerated approval of the ALK TKI crizotinib or Xalkori (Pfizer, NY, NY) when clinical trials demonstrated that it resulted in improved RR and PFS in patients with advanced NSCLC with ALK rearrangements [16•, 17]. Simultaneously, the FDA approved a specific companion test (Vysis ALK Break-Apart FISH Probe Kit from Abbott Molecular, Des Plaines, IL) used to select patients for therapy with crizotinib in the clinical trials [18]. For ALK testing, cytogenetic techniques such as FISH are generally preferred over reverse transcriptase polymerase chain reaction (RT-PCR) or other non-cytogenetic methods due to the number of variants of $A L K$ fusions with $E M L 4$ and the fusion of $A L K$ with partner genes other than $E M L 4$. RTPCR requires separate primers for each possible $A L K$ fusion gene and, therefore, unless primers are used for every possible fusion, some variants will be missed [17, 19].

Despite the exciting initial clinical trial results, there are a number of significant shortcomings with these first generation TKIs. First, in the United States, only $\sim 15 \%$ of NSCLC have EGFR mutations and $\sim 4 \%$ of NSCLC have ALK rearrangements. That is, no targeted therapies are available for the remaining $81 \%$ of NSCLC [13]. Second, EGFR mutations and ALK rearrangements occur almost exclusively in adenocarcinomas, including adenosquamous carcinomas, and uncommonly in pure squamous cell carcinomas or pure small cell carcinomas [3, 4, 12, 13, 20, 21]. Finally, after a period of initial response of several months, most NSCLC develop acquired resistance to EGFR TKIs or crizotinib due to secondary mutations in the EGFR or $A L K$ gene or other mechanisms. These patients then require second- or third-line therapies for which second generation TKIs or drugs directed at other molecular targets might be considered [22,23]. Therefore, these early successes in lung cancer targeted therapy and associated predictive biomarker testing are only initial steps towards lung cancer precision medicine. Advances in predictive biomarker technology, as well as the search for new drugs and new clinically actionable targets, are rapidly progressing to address patient needs.

\section{Advances in Predictive Biomarker Technology}

\section{Next Generation Sequencing}

Until recently, clinical laboratories had limited options for genotyping tumor specimens. These mostly encompassed laboratory-developed tests using traditional molecular diagnostics technologies, such as polymerase chain reaction (PCR) coupled with sequence-specific hybridization probes or fragment analysis, Sanger dideoxynucleotide chain termination sequencing, and pyrosequencing [24]. Although these assays continue to perform well and have been crucial to improving patient care, they are hampered by a single-target-gene approach that requires a separate assay be performed for each biomarker. Thus, when specimen volumes are limited (i.e., transbronchial biopsies), there may be insufficient material to perform all needed gene mutation (i.e. EGFR, ALK, and PIK3CA gene mutations) and gene rearrangement (i.e., $A L K$ and ROSI gene rearrangements) testing. In this context, "next-generation" sequencing technologies are revolutionizing the field of molecular diagnostics. The laboratory can now very quickly and inexpensively generate highly multiplexed tumor genotypes in a single reaction that uses as little as 10-250 ng of input genomic DNA [25].

Several "next-generation" DNA sequencing platforms are commercially available. In general, they can be categorized into two groups based on the type of DNA molecule used as a template. The instruments most commonly used in clinical laboratories produce libraries of clonally amplified targets. That is, each DNA fragment in the extracted specimen is first amplified and then sequenced in parallel, leading to the term "massively parallel sequencing". These instruments include the 454 GS Junior (454 Life Sciences, Roche, Branford, CT), Ion Torrent Personal Genome Machine (Ion Torrent Systems, Life Technologies, San Francisco, CA), and MiSeq Personal Sequencer (Illumina Inc, San Diego, CA). Assay reagent kits licensed for Research Use Only (RUO) can be purchased to perform highly multiplexed tumor genotyping on each of these instruments. Single-molecule sequencing platforms such as the PacBio RS (Pacific Biosciences, Menlo Park, CA) have more recently emerged in the research environment. Although a powerful tool for whole-genome sequencing, their role in the molecular diagnostics laboratory remains uncertain. The MassARRAY Analyzer (Sequenom Inc, San Diego, CA) is another attractive option for clinical laboratories. Rather than sequencing DNA, the MassARRAY 
Analyzer uses mass spectrometry of amplified gene fragments to determine their genotype. Beadling et al. [26] demonstrated the power of this approach by genotyping 820 tumors selected from a cancer registry, identifying several unexpected mutations that could be clinically actionable. In addition, investigators have recently developed novel strategies to detect gene rearrangements on the MassARRAY Analyzer, making it possible to concurrently evaluate gene mutations and gene rearrangements in a single run [27]. Although each of the instruments discussed herein generates high-quality sequence data, they vary in technical performance and laboratory operation characteristics including throughput, read length, error rate, handson time, run time, instrument cost and reagent cost. Based on the particular need and intended application, we recommend that each pathology laboratory carefully evaluate the options and direct the reader to a recent review on this complex analysis [28•]. To assist pathologists in implementing these new technologies in the clinical environment, the College of American Pathologists (CAP) recently convened an expert panel and released a next-generation sequencing checklist (www.cap.org).

Although still in its infancy as a diagnostic tool, wholegenome sequencing has the potential to truly personalize patient care, moving us ever closer to the goal of precision medicine in lung cancer. The long-sought $\$ 1,000$ genome is nearly a reality, and advances in laboratory automation and bioinformatics analysis are making genomics an increasingly tractable tool for routine patient care [29]. Two large research studies recently published the whole genome sequences of 183 lung adenocarcinomas and 178 lung squamous cell carcinomas, respectively [30•, 31•]. These incredibly rich datasets revealed the tremendous level of genomic complexity in lung cancer. They also identified numerous opportunities for the application of existing and the development of new targeted therapies. For example, investigators not only confirmed the frequent presence of EGFR, KRAS and BRAF mutations in lung adenocarcinoma, but they also identified previously unrecognized recurrent mutations in several genes including U2AF1, RBM10 and ARIDIA [31]. In total, 25 genes were determined to be significantly mutated in lung adenocarcinoma. That is, whole-genome sequencing identified a very promising panel of adenocarcinoma genes for further study. In comparison, only 11 genes were shown to have statistically recurrent mutations in lung squamous cell carcinoma [30]. Among these, P53, PIK3CA and NOTCH1 were already noted above. However, multiple significantly altered pathways were also identified, including pathways implicated in oxidative stress response and squamous cell differentiation. Of note, many of these alterations are shared with head and neck squamous cell carcinomas, suggesting a possible similarity in their underlying biology and therapeutic vulnerabilities. Thus, new avenues for investigating biologic basis and therapeutic targeting in adenocarcinoma were discovered. Taken together, these studies reveal that potentially druggable targets can be found in nearly every lung tumor. Furthermore, as the comprehensive catalogue of somatic gene mutations associated with particular lung tumor types is complemented with epigenetic, transcriptomic, proteomic and metabolomic signatures, our understanding of malignant transformation and predictable clinical phenotypes will expand. This research is expected to produce increasingly innovative and effective therapeutic strategies that will profoundly affect patient care.

Inasmuch as pathologists can generate tremendous amounts of data using next-generation sequencing, information management and interpretation is an ongoing challenge. Given the magnitude of the human genome (approximately three billion base pair encoding $\sim 20,000$ genes), investigators are increasingly building bioinformatics and statistics support into their clinical laboratories. Improved bioinformatics pipelines and automated analysis algorithms must be developed before whole genome sequencing data can be evaluated in a timeframe that is optimal for patient care. A further challenge will be to learn which gene alterations identified in a particular tumor are driver mutations versus bystander mutations, emphasizing the need for continued molecular biology research. Coordinated efforts to generate a comprehensive reference human genome sequence and cancer genome databases (http://cancergenome.nih.gov, http:// cancercommons.org, and http://icgc.org) have begun filling this knowledge gap. Results from these initiatives will be crucial for translating research discoveries to clinically meaningful interpretations. Moreover, investigators are increasingly learning that any one cancer is not homogenous, with concurrent existence of multiple subclonal lineages. To fully evaluate the possible efficacy of targeted therapy for a patient, the pathologist may need to analyze multiple samples collected at serial time points.

\section{Predictive Biomarker Immunohistochemistry (IHC)}

Until recently, the use of IHC to identify EGFR mutations and $A L K$ rearrangements in lung cancers has been problematic. Traditional EGFR IHC detects generic protein expression without differentiating between wild-type and mutant epitopes, so it has not proven reliable in selecting candidates for EGFR TKI therapy. Antibodies to proteins associated with specific EGFR mutations are under investigation. Generally, these antibodies recognize the two primary mutations that account for approximately $90 \%$ of EGFR mutations associated with a response to EGFR TKIs. Thus, IHC may be a useful screening tool, but it fails 
to detect the $10 \%$ of patients whose lung cancers have less commonly identified EGFR mutations. Investigations are ongoing in this field. [32-34]

ALK expression is not detected by IHC in the vast majority of benign tissues that lack an $A L K$ fusion gene. However, it is detected by IHC when an $A L K$ fusion gene is present, including in lymphoma, solitary fibrous tumor and other tumors. However, traditional ALK IHC has sometimes failed to detect ALK expression in lung cancers that were subsequently proven to have $A L K$ fusion genes by other techniques, presumably due to the comparatively low expression of ALK in lung cancers. Various techniques have been proposed to enhance the sensitivity of ALK IHC for lung cancers, but an important development has been the recent availability of ALK antibodies that are highly specific and sensitive to ALK expression in lung cancers such as ALK (D5F3) XP ${ }^{\circledR}$ Rabbit mAb (Biotinylated) \#8936 (Cell Signaling Technology, Danvers, MA). Although the correlation of ALK expression with ALK rearrangements is established, clinical trials directly comparing ALK IHC results to patient outcomes with crizotinib have not yet been performed [35-37].

\section{New Drugs}

\section{Cetuximab}

Cetuximab (Erbitux; Bristol-Myers Squibb, NY, NY, and Eli Lilly and Company, Indianapolis, IN) is not a new drug, having been approved by the FDA for treatment of advanced colon adenocarcinoma and advanced head and neck squamous cell carcinoma [38-42]. However, it has been recently repurposed to lung cancer therapy [43]. Cetuximab is an anti-EGFR monoclonal antibody, offering a different approach to anti-EGFR therapy from the currently approved EGFR TKIs. In the first line Erbitux in lung cancer (FLEX) clinical trials, overall differences in patient response and outcomes for advanced NSCLC were not impressive. Further analysis disclosed a subgroup of patients who were likely to benefit from the addition of cetuximab with EGFR IHC as the predictive biomarker test. The level of EGFR expression in NSCLC correlated with an increased overall survival in advanced NSCLC patients receiving first-line chemotherapy plus cetuximab versus chemotherapy alone if the cancer had an EGFR IHC score of 200 or more using the Dako pharmDx kit (Glostrup, Denmark) [44-46]. The Southwest Oncology Group (SWOG) study SO342 and Phase III trial SO819 suggested that EGFR FISH might also be a predictive biomarker for advanced NSCLC patients receiving cetuximab plus chemotherapy [47, 48].
ERBB Family Blockers

Since first-generation EGFR TKIs eventually become ineffective due to acquired resistance, second-generation EGFR TKIs, which are actually ERBB family blockers, are under development. These agents are currently undergoing advanced clinical trials as adjuvant lines of therapy and/or first-line therapy. Second generation EGFR TKIs are potentially superior to first-generation EGFR TKIs, due to their higher affinity for the target, irreversible binding to the target, and inhibition of more than one target in the ERBB family of receptors. ERBB family blockers under study include dacomitinib [49], XL647 [50] and afatinib (BIBW2992: Boehringer Ingelheim, Ingelheim, Germany) [51-54]. Afatinib irreversibly binds to EGFR, even with the most common acquired resistance mutation (T790M) [51-54].

\section{Drugs that Inhibit Multiple Targets}

Some drugs inhibit more than one target and thus may be repurposed. It is anticipated that crizotinib, already approved for treatment of ALK-positive NSCLC, will be approved for treatment of ROS1 positive NSCLC. Crizotinib is not only an ALK TKI, but also inhibits other tyrosine kinases that may be present in NSCLC, including ROS1, MET and RON $[55,56]$. ROS1 rearrangements are detected in a small percentage of NSCLC by FISH, and as with ALK, several different fusion partners have been identified $[56,57]$.

\section{New Druggable Targets}

\section{Genotype Based Therapy Under Investigation}

Additional druggable targets are needed to be discovered for the lung cancers that do not respond to or become resistant to TKIs. A number of targets, including the signaling pathways downstream of ERRB receptors are being investigated. However, no drug that is effective against the most frequently mutated oncogene in adenocarcinoma of the lung, KRAS, has been discovered [58].

Targets in the PI3K/AKT/mTOR pathway have received considerable recent attention. Several drugs impacting targets in this pathway are undergoing clinical trial, including the mTOR inhibitor everolimus, the PI3K and mTOR inhibitor BEZ235, the PI3K inhibitors GDC-0941 and XL147and the AKT inhibitor MK-2206 [59-62]. Several inhibitors and antibodies are under investigation for c-MET and its ligand, hepatocyte growth factor or HGF [63]. The Met Inhibitor ARQ 197 plus Erlotinib vs. Erlotinib (MARQUEE plus placebo in NSCLC) trial is investigating the c-MET TKI ARQ 197 (also known as tivantinib) as 
second-line therapy in patients with advanced non-squamous NSCLC $[64,65]$. Potential drugs suggested for members of the IL-6/JAK/STAT pathway include the JAK inhibitors enzastaurin and AZD1480 and the STAT inhibitor NSC743380 [66-68]. MEK has also been investigated as a potential downstream target with modest results to date [69-71]. Other proposed TKIs and their corresponding targets include vandetanib for RET $[72,73]$ and dasatinib for Src $[74,75]$.

\section{Genotype Based Therapy in Cell Types Other than Adenocarcinoma}

The initial success with first generation TKIs for EGFR mutations and ALK rearrangements has been confined to adenocarcinomas, including adenosquamous cell carcinomas, but has not been applicable to pure squamous cell carcinomas or pure small-cell carcinomas. The search for druggable targets and corresponding TKIs for squamous cell carcinoma has led to intense interest in members of the PI3K pathway, the fibroblast growth factor receptor and the discoidin domain receptor, accounting for about $20-30 \%, 20 \%$ and $4 \%$ of squamous cell carcinomas, respectively [30, 76-78]. It remains to be seen if these likely targets will respond to TKI therapy. Another approach to "targeted therapy" for squamous cell carcinoma (as well as other cell types) may be the targeting of the abundant folate receptors on the cell surface of most squamous cell carcinomas. Novel delivery molecules are being designed to specifically deliver chemotherapeutic drugs attached to folate [79]. The mTOR inhibitors everolimus and temsirolimus are also under investigation as possible therapies for small-cell lung cancer [80-82].

\section{Molecular Targeting of Lung Cancer Stem Cells}

Lung cancer stem cells represent a cancer cell population that has the ability to self-renew. These cells frequently are chemoresistant. Post-chemoradiotherapy expression of lung cancer stem cell markers has been shown recently to significantly correlate with poor prognosis in lung cancer patients [83]. There is increasing evidence that cancer stem cells, including lung cancer stem cells, play a critical role in drug resistance, tumor regeneration, and metastasis [84]. Their asymmetric cell division and slow cycling makes identification and treatment targeting these cancer stem cells challenging [84]. Identification of molecular targets for effective lung cancer stem cell therapy requires the differentiation of lung cancer stem cells from normal multipotent stem cells. This differentiation might be accomplished using magnetic bead isolation or flow cytometry to identify unique cell type markers [85].

As cancers have traditionally been treated with the assumption that all cancer cells have equal malignant potential, the concept that cancers are driven by cancer stem cells has significant clinical implications [86]. Researchers are actively seeking therapies that target stem cells, and cancer stem cell inhibitory mechanisms such as blocking stem cell factor, antagonizing ABCG2 pumping activity, and inhibition Notch activity are becoming increasingly studied [86]. Specifically, Notch, Wnt, and Hedgehog pathways are important in stem cell regulation [84]. An activated Notch pathway has been identified in approximately one-third of lung cancer cases and shown to indicate a significantly worse prognosis in patients lacking a concomitant p53 mutation [84]. Wnt signaling activation produces significantly enhanced proliferation, colony formation, migration, and drug resistance. It is also vital to embryogenesis and homeostatic maintenance of adult tissues [84, 87•]. The Hedgehog signaling pathway plays a key role in determining whether a cell undergoes differentiation or self-renewal [87]. Studies of lung cancer stem cell targeted therapy based on these pathways is ongoing, and researchers are actively pursuing targeted therapies [87].

Studies of additional possible lung cancer stem-celltargeted therapies are ongoing. For example, Rac1 GTPase activity was recently shown to be significantly increased in cancer cells that have undergone epithelial-mesenchymal transition. Targeting Rac1 might provide a more effective lung cancer therapy by eliminating cancer stem cell subpopulations and by blocking non-cancer stem-cell-tocancer stem cell transition [88]. Also, ALDH1A1 positivity in lung cancer stem cells may cause lung cancer resistance to EGFR-TKI [89•]. Similarly, phenothiazine-like antipsychotic drug trifluoperazien was recently shown to down-regulate cancer stem cell markers CD44 and CD133, conferring anti-lung cancer stem cell properties that might overcome chemotherapy- and EGFR-TKI resistance [90].

\section{Conclusion}

An ever-increasing number of predictive biomarker tests will require greater knowledge and participation of the pathologist in personalized healthcare of the lung cancer patient. The pathologist must be prepared to advise clinicians on selection of the most appropriate tests and decide how to most effectively triage pathology samples, particularly small biopsies and cytology specimens. Pathologists must also continue developing highly multiplexed testing to efficiently use available tissue resources and reduce turnaround times. With the advent of additional lines of therapy, particularly in response to acquired resistance to initial therapy, the pathologist may potentially have an increased workload of sequential biopsies from a given patient over time. This may be particularly true as surveillance protocols are increasingly used to detect secondary mutations associated with acquired resistance prior to relapse [91, 92]. 
The role of the pathologist may also significantly evolve as IHC markers become better established. IHC is readily accessible to the community pathologist, enabling both diagnosis and predictive biomarkers analysis by direct observation of malignant cells using conventional tools and procedures. IHC appears to be the appropriate predictive biomarker methodology for cetuximab therapy. Also, the availability of antibodies to ALK overexpression and the ongoing validation of antibodies against other predictive biomarkers such as specific EGFR mutations makes IHC increasing tractable to the anatomic pathologist [4, 93, 94].

Disclosure No potential conflicts of interest relevant to this article were reported.

\section{References}

Papers of particular interest, published recently, have been highlighted as:

- Of importance

1. Siegel R, Naishadham D, Jemal A (2012) Cancer statistics, 2012. CA Cancer J Clin 62(1):10-29

2. Youlden DR, Cramb SM, Baade PD (2008) The international epidemiology of lung cancer: geographical distribution and secular trends. J Thorac Oncol 3:819-831

3. Cagle PT, Allen TC, Dacic S et al (2011) Revolution in lung cancer: new challenges for the surgical pathologist. Arch Pathol Lab Med 135:110-116

4. Cagle PT, Dacic S (2011) Lung cancer and the future of pathology. Arch Pathol Lab Med 135:293-295

5. Sobol RE, Astarita RW, Hofeditz C et al (1987) Epidermal growth factor receptor expression in human lung carcinomas defined by a monoclonal antibody. J Natl Cancer Inst 79:403-407

6. Lynch TJ, Bell DW, Sordella R et al (2004) Activating mutations in the epidermal growth factor receptor underlying responsiveness of non-small-cell lung cancer to gefitinib. N Engl J Med 350:2129-2139

7. Paez JG, Janne PA, Lee JC et al (2004) EGFR mutations in lung cancer: correlation with clinical response to gefitinib therapy. Science 304:1497-1500

8. Pao W, Miller V, Zakowski M et al (2004) EGF receptor gene mutations are common in lung cancers from "never smokers" and are associated with sensitivity of tumors to gefitinib and erlotinib. Proc Natl Acad Sci USA 101:13306-13311

9. - Mok TS, Wu YL, Thongprasert S, et al. (2009) Gefitinib or carboplatin-paclitaxel in pulmonary adenocarcinoma. N Engl J Med 361:947-957. Report on the Iressa Pan-Asia Study. This is seminal report disclosing that EGFR gene mutation in lung cancer is a strong predictor of a better outcome with gefitinib compared to conventional chemotherapy.

10. Mitsudomi T, Morita S, Yatabe Y et al (2010) Gefitinib versus cisplatin plus docetaxel in patients with non-small-cell lung cancer harbouring mutations of the epidermal growth factor receptor (WJTOG3405): an open label, randomised phase 3 trial. Lancet Oncol 11:121-128

11. Maemondo M, Inoue A, Kobayashi K et al (2010) Gefitinib or chemotherapy for non-small-cell lung cancer with mutated EGFR. N Engl J Med 362:2380-2388
12. Chirieac LR, Dacic S (2010) Targeted therapies in lung cancer. Surg Pathol Clin 3:71-82

13. Gaughan EM, Costa DB (2011) Genotype-driven therapies for non-small cell lung cancer: focus on EGFR, KRAS and ALK gene abnormalities. Ther Adv Med Oncol 3:113-125

14. Soda M, Choi YL, Enomoto M et al (2007) Identification of the transforming EML4-ALK fusion gene in non-small-cell lung cancer. Nature 448:561-566

15. Togashi Y, Soda M, Sakata S et al (2012) KLC1-ALK: A novel fusion in lung cancer identified using a formalin-fixed paraffinembedded tissue only. PLoS One 7:e31323

16. - Kwak EL, Bang YJ, Camidge DR, et al. (2010) Anaplastic lymphoma kinase inhibition in non-small cell lung cancer. N Eng J Med 363:1693-1703. Seminal report on effect of ALK inhibition with critzotinib on lung cancers with ALK rearrangements.

17. Shaw AT, Yeap BY, Solomon BJ et al (2011) Effect of crizotinib on overall survival in patients with advanced non-small-cell lung cancer harbouring ALK gene rearrangement: a retrospective analysis. Lancet Oncol 12:1004-1012

18. Shaw AT, Solomon B, Kenudson MM (2011) Crizotinib and testing for ALK. J Natl Compr Canc Netw 9:1335-1341

19. Bang YJ (2011) The potential for crizotinib in non-small cell lung cancer: a perspective review. Ther Adv Med Oncol 3:279-291

20. Rekhtman N, Paik PK, Arcila ME et al (2012) Clarifying the spectrum of driver oncogene mutations in biomarker-verified squamous carcinoma of lung: lack of EGFR/KRAS and presence of PIK3CA/AKT1 mutations. Clin Cancer Res 18:1167-1176

21. Tochigi N, Dacic S, Nikiforova M, Cieply KM, Yousem SA (2011) Adenosquamous carcinoma of the lung: a microdissection study of KRAS and EGFR mutational and amplification status in a western patient population. Am J Clin Pathol 135:783-789

22. Katayama R, Shaw AT, Khan TM, et al. (2012) Mechanisms of acquired crizotinib resistance in ALK-rearranged lung cancers. Sci Transl Med 4:120ra17

23. Zhang Z, Lee JC, Lin L et al (2012) Activation of the AXL kinase causes resistance to EGFR-targeted therapy in lung cancer. Nat Genet 44:852-860

24. Tsiatis AC, Norris-Kirby A, Rich RG et al (2010) Comparison of Sanger sequencing, pyrosequencing, and melting curve analysis for the detection of KRAS mutations: diagnostic and clinical implications. J Mol Diagn 12:425-432

25. Feero WG, Green ED (2011) Genomics education for health care professionals in the 21st century. J Am Med Assoc 306:989-990

26. Beadling C, Heinrich MC, Warrick A et al (2011) Multiplex mutation screening by mass spectrometry evaluation of 820 cases from a personalized cancer medicine registry. J Mol Diagn 13:504-513

27. Sakai K, Okamoto I, Takezawa K et al (2012) A novel mass spectrometry-based assay for diagnosis of EML4-ALK-positive non-small cell lung cancer. J Thorac Oncol 7:913-918

28. • Loman NJ, Misra RV, Dallman TJ, et al. (2012) Performance comparison of benchtop high-throughput sequencing platforms. Nat Biotechnol 30:434-439. This study compared the performance characteristics of three benchtop next-generation sequencing instruments by sequencing the genome of a strain of Escherichia coli recovered from the food poisoning outbreak in Germany in 2011. Results highlight the strengths and limitations of each instrument.

29. McDermott U, Downing JR, Stratton MR (2011) Genomics and the continuum of cancer care. N Engl J Med 364:340-350

30. - Cancer Genome Atlas Research Network, Hammerman PS, Hayes DN, et al. (2012) Comprehensive genomic characterization of squamous cell lung cancers. Nature 489:519-525. Investigators sequenced the genomes of 178 lung squamous cell carcinomas to comprehensively identify genetic alterations including gene mutations, gene rearrangements and copy number 
alterations. A potentially clinically actionable target was found in most tumors.

31. - Imielinski M, Berger AH, Hammerman PS, et al. (2012) Mapping the hallmarks of lung adenocarcinoma with massively parallel sequencing. Cell 150:1107-1120. Investigators sequenced the exome or genome of 183 lung adenocarcinomas. In addition to confirming the genes previously identified as being frequently mutated, numerous candidate gene alterations for further biological characterization and possible therapeutic targeting were identified.

32. Brevet M, Arcila M, Ladanyi M (2010) Assessment of EGFR mutation status in lung adenocarcinoma by immunohistochemistry using antibodies specific to the two major forms of mutant EGFR. J Mol Diagn 12:169-176

33. Hasanovic A, Ang D, Moreira AL, Zakowski MF (2012) Use of mutation specific antibodies to detect EGFR status in small biopsy and cytology specimens of lung adenocarcinoma. Lung Cancer 77:299-305

34. Yu J, Kane S, Wu J et al (2009) Mutation-specific antibodies for the detection of EGFR mutations in non-small-cell lung cancer. Clin Cancer Res 15:3023-3028

35. Boland JM, Erdogan S, Vasmatzis G et al (2009) Anaplastic lymphoma kinase immunoreactivity correlates with ALK gene rearrangement and transcriptional up-regulation in non-small cell lung carcinomas. Hum Pathol 40:1152-1158

36. Mino-Kenudson M, Chirieac LR, Law K et al (2010) A novel, highly sensitive antibody allows for the routine detection of ALK-rearranged lung adenocarcinomas by standard immunohistochemistry. Clin Cancer Res 16:1561-1571

37. Yi ES, Boland JM, Maleszewski JJ et al (2011) Correlation of IHC and FISH for ALK gene rearrangement in non-small cell lung carcinoma: IHC score algorithm for FISH. J Thorac Oncol 6:459-465

38. Eng C (2010) The evolving role of monoclonal antibodies in colorectal cancer: early presumptions and impact on clinical trial development. Oncologist 15:73-84

39. Mehra R, Cohen RB, Burtness BA (2008) The role of cetuximab for the treatment of squamous cell carcinoma of the head and neck. Clin Adv Hematol Oncol 6:742-750

40. Moon C, Chae YK, Lee J (2010) Targeting epidermal growth factor receptor in head and neck cancer: lessons learned from cetuximab. Exp Biol Med (Maywood) 235:907-920

41. Vincenzi B, Zoccoli A, Pantano F, Venditti O, Galluzzo S (2010) Cetuximab: From bench to bedside. Curr Cancer Drug Targets 10:80-95

42. Wong SF (2005) Cetuximab: an epidermal growth factor receptor monoclonal antibody for the treatment of colorectal cancer. Clin Ther 27:684-694

43. Carillio G, Montanino A, Costanzo R et al (2012) Cetuximab in non-small-cell lung cancer. Expert Rev Anticancer Ther 12:163-175

44. Pirker R, Pereira JR, Szczesna A et al (2012) Prognostic factors in patients with advanced non-small cell lung cancer: data from the phase III FLEX study. Lung Cancer 77:376-382

45. • Pirker R, Pereira JR, von Pawel J, et al. (2012) EGFR expression as a predictor of survival for first-line chemotherapy plus cetuximab in patients with advanced non-small-cell lung cancer: analysis of data from the phase 3 FLEX study. Lancet Oncol 13(1):33-42. Seminal report disclosing that increased EGFR expression documented by IHC predicts response to cetuximab in patients with advanced NSCLC.

46. O’Byrne KJ, Gatzemeier U, Bondarenko I et al (2011) Molecular biomarkers in non-small-cell lung cancer: a retrospective analysis of data from the phase 3 FLEX study. Lancet Oncol 12:795-805

47. Herbst RS, Kelly K, Chansky K et al (2010) Phase II selection design trial of concurrent chemotherapy and cetuximab versus chemotherapy followed by cetuximab in advanced-stage nonsmall-cell lung cancer: southwest oncology group study S0342. J Clin Oncol 28:4747-4754

48. Redman MW, Crowley JJ, Herbst RS, Hirsch FR, Gandara DR (2012) Design of a phase III clinical trial with prospective biomarker validation: SWOG S0819. Clin Cancer Res 18:4004-4012

49. Ramalingam SS, Blackhall F, Krzakowski M et al (2012) Randomized phase II study of dacomitinib (PF-00299804), an irreversible pan-human epidermal growth factor receptor inhibitor, versus erlotinib in patients with advanced non-small-cell lung cancer. J Clin Oncol 30:3337-3344

50. Pietanza MC, Lynch TJ Jr, Lara PN Jr et al (2012) XL647-a multitargeted tyrosine kinase inhibitor: results of a phase II study in subjects with non-small cell lung cancer who have progressed after responding to treatment with either gefitinib or erlotinib. J Thorac Oncol 7:219-226

51. Brugger W, Thomas M (2012) EGFR-TKI resistant non-small cell lung cancer (NSCLC): new developments and implications for future treatment. Lung Cancer 77:2-8

52. Hirsch FR, Bunn PA Jr (2012) A new generation of EGFR tyrosine-kinase inhibitors in NSCLC. Lancet Oncol 13:442-443

53. Langer CJ, Mok T, Postmus PE (2012) Targeted agents in the third-/fourth-line treatment of patients with advanced (stage III/ IV) non-small cell lung cancer (NSCLC). Cancer Treat Rev. doi: 10.1016/j.ctrv.2012.05.003

54. Yang JC, Shih JY, Su WC et al (2012) Afatinib for patients with lung adenocarcinoma and epidermal growth factor receptor mutations (LUX-lung 2): a phase 2 trial. Lancet Oncol 13: 539-548

55. Takeuchi K, Soda M, Togashi Y et al (2012) RET, ROS1 and ALK fusions in lung cancer. Nat Med 18:378-381

56. Yasuda H, de Figueiredo-Pontes LL, Kobayashi S, Costa DB (2012) Preclinical rationale for use of the clinically available multitargeted tyrosine kinase inhibitor crizotinib in ROS1-translocated lung cancer. J Thorac Oncol 7:1086-1090

57. Janne PA, Meyerson M (2012) ROS1 rearrangements in lung cancer: a new genomic subset of lung adenocarcinoma. J Clin Oncol 30:878-879

58. Adjei AA (2008) K-ras as a target for lung cancer therapy. J Thorac Oncol 3:S160-S163

59. Reungwetwattana T, Molina JR, Mandrekar SJ et al (2012) Brief report: a phase II "window-of-opportunity" frontline study of the mTOR inhibitor, temsirolimus given as a single agent in patients with advanced NSCLC, an NCCTG study. J Thorac Oncol 7:919-922

60. Xu CX, Li Y, Yue P et al (2011) The combination of RAD001 and NVP-BEZ235 exerts synergistic anticancer activity against non-small cell lung cancer in vitro and in vivo. PLoS One 6:e20899

61. Zito CR, Jilaveanu LB, Anagnostou V et al (2012) Multi-level targeting of the phosphatidylinositol-3-kinase pathway in nonsmall cell lung cancer cells. PLoS One 7:e31331

62. Zou ZQ, Zhang LN, Wang F, Bellenger J, Shen YZ, Zhang XH (2012) The novel dual PI3K/mTOR inhibitor GDC-0941 synergizes with the MEK inhibitor U0126 in non-small cell lung cancer cells. Mol Med Rep 5:503-508

63. Sierra JR, Tsao MS (2011) c-MET as a potential therapeutic target and biomarker in cancer. Ther Adv Med Oncol 3:S21-S35

64. Scagliotti GV, Novello S, Schiller JH et al (2012) Rationale and design of MARQUEE: a phase III, randomized, double-blind study of tivantinib plus erlotinib versus placebo plus erlotinib in previously treated patients with locally advanced or metastatic, nonsquamous, non-small-cell lung cancer. Clin Lung Cancer 13:391-395

65. Sequist LV, von Pawel J, Garmey EG et al (2011) Randomized phase II study of erlotinib plus tivantinib versus erlotinib plus 
placebo in previously treated non-small-cell lung cancer. J Clin Oncol 29:3307-3315

66. Rde OA, Cagle PT, Jagirdar J (2007) Expression of activated and latent signal transducer and activator of transcription 3 in 303 non-small cell lung carcinomas and 44 malignant mesotheliomas: possible role for chemotherapeutic intervention. Arch Pathol Lab Med 131:1350-1360

67. Shimokawa T, Seike M, Soeno C et al (2012) Enzastaurin has anti-tumour effects in lung cancers with overexpressed JAK pathway molecules. Br J Cancer 106:867-875

68. Zhang X, Yue P, Page BD et al (2012) Orally bioavailable smallmolecule inhibitor of transcription factor Stat3 regresses human breast and lung cancer xenografts. Proc Natl Acad Sci USA 109:9623-9628

69. Tanizaki J, Okamoto I, Takezawa K et al (2012) Combined effect of ALK and MEK inhibitors in EML4-ALK-positive non-smallcell lung cancer cells. Br J Cancer 106:763-767

70. Dy G (2010) MEK/MAPK inhibitors. J Thorac Oncol 5:S474S475

71. Haura EB, Ricart AD, Larson TG et al (2010) A phase II study of PD-0325901, an oral MEK inhibitor, in previously treated patients with advanced non-small cell lung cancer. Clin Cancer Res 16:2450-2457

72. Kohno T, Ichikawa H, Totoki Y et al (2012) KIF5B-RET fusions in lung adenocarcinoma. Nat Med 18:375-377

73. Ju YS, Lee WC, Shin JY et al (2012) A transforming KIF5B and RET gene fusion in lung adenocarcinoma revealed from wholegenome and transcriptome sequencing. Genome Res 22:436-445

74. Kruser TJ, Traynor AM, Wheeler DL (2011) The use of singleagent dasatinib in molecularly unselected non-small-cell lung cancer patients. Expert Opin Investig Drugs 20:305-307

75. Johnson ML, Riely GJ, Rizvi NA et al (2011) Phase II trial of dasatinib for patients with acquired resistance to treatment with the epidermal growth factor receptor tyrosine kinase inhibitors erlotinib or gefitinib. J Thorac Oncol 6:1128-1131

76. Drilon A, Rekhtman N, Ladanyi M, Paik P (2012) Squamous-cell carcinomas of the lung: emerging biology, controversies, and the promise of targeted therapy. Lancet Oncol 13:e418-e426

77. Paik PK, Varghese AM, Sima CS et al (2012) Response to erlotinib in patients with EGFR mutant advanced non-small cell lung cancers with a squamous or squamous-like component. Mol Cancer Ther 11:2535-2540

78. Perez-Moreno P, Brambilla E, Thomas R, Soria JC (2012) Squamous cell carcinoma of the lung: molecular subtypes and therapeutic opportunities. Clin Cancer Res 18:2443-2451

79. Cagle PT, Zhai QJ, Murphy L, Low PS (2012) Folate receptor in adenocarcinoma and squamous cell carcinoma of the lung: potential target for folate-linked therapeutic agents. Arch Pathol Lab Med. doi:10.5858/arpa.2012-0176-OA

80. Schmid K, Bago-Horvath Z, Berger W et al (2010) Dual inhibition of EGFR and mTOR pathways in small cell lung cancer. $\mathrm{Br} \mathbf{J}$ Cancer 103:622-628
81. Sher T, Dy GK, Adjei AA (2008) Small cell lung cancer. Mayo Clin Proc 83:355-367

82. Tarhini A, Kotsakis A, Gooding W et al (2010) Phase II study of everolimus (RAD001) in previously treated small cell lung cancer. Clin Cancer Res 16:5900-5907

83. Shien K, Toyooka S, Ichimura K et al (2012) Prognostic impact of cancer stem cell-related markers in non-small cell lung cancer patients treated with induction chemoradiotherapy. Lung Cancer 77:162-167

84. Gottschling S, Schnabel PA, Herth FJ, Herpel E (2012) Are we missing the target? Cancer stem cells and drug resistance in nonsmall cell lung cancer. Cancer Genomics Proteomics 9:275-286

85. Gadepalli VS, Vaughan C, Rao RR (2013) Isolation and characterization of murine multipotent lung stem cells. Methods Mol Biol 962:183-191

86. Nurwidya F, Murakami A, Takahashi F, Takahashi K (2012) Lung cancer stem cells: tumor biology and clinical implications. Asia Pac J Clin Oncol 8:217-222

87. • Lundin A, Driscoll B (2012) Lung cancer stem cells: progress and prospects. Cancer Lett. doi:10.1016/j.canlet.2012.08.014 The authors examine the abnormal activation of Wnt, Notch, and Hedgehog pathways in lung cancer stem cells and the potential of therapies specifically targeting stem cell signaling pathways.

88. Akunuru S, James Zhai Q, Zheng Y (2012) Non-small cell lung cancer stem/progenitor cells are enriched in multiple distinct phenotypic subpopulations and exhibit plasticity. Cell Death Dis 3:e352

89. - Huang CP, Tsai MF, Chang TH, et al. (2013) ALDH-positive lung cancer stem cells confer resistance to epidermal growth factor receptor tyrosine kinase inhibitors. Cancer Lett 328:144-151. The study suggests that ALDH1A1 positivity in lung cancer stem cells confers resistance to EGFR tyrosine kinase inhibitors.

90. Yeh CT, Wu AT, Chang PM, et al. (2012) Trifluoperazine, an antipsychotic agent, inhibits cancer stem cell growth and overcomes drug resistance of lung cancer. Am J Respir Crit Care Med 186:1180-1188.

91. Arcila ME, Oxnard GR, Nafa K et al (2011) Rebiopsy of lung cancer patients with acquired resistance to EGFR inhibitors and enhanced detection of the T790M mutation using a locked nucleic acid-based assay. Clin Cancer Res 17:1169-1180

92. Oxnard GR (2012) Strategies for overcoming acquired resistance to epidermal growth factor receptor: targeted therapies in lung cancer. Arch Pathol Lab Med 136:1205-1209

93. Cagle PT, Myers J (2012) Precision medicine for lung cancer: role of the surgical pathologist. Arch Pathol Lab Med 136:1186-1189

94. Cagle PT, Chirieac LR (2012) Advances in treatment of lung cancer with targeted therapy. Arch Pathol Lab Med 136:504-509 